\title{
Erratum to: Wavelets Centered on a Knot Sequence: Theory, Construction, and Applications
}

\author{
Bruce W. Atkinson • Derek O. Bruff • Jeffrey S. Geronimo • \\ Douglas P. Hardin
}

Published online: 21 February 2015

(C) Springer Science+Business Media New York 2015

\section{Erratum to: J Fourier Anal Appl DOI 10.1007/s00041-014-9375-9}

In the article, the first author's name is listed incorrectly. It should be Bruce W. Atkinson.

The online version of the original article can be found under doi:10.1007/s00041-014-9375-9.

B. W. Atkinson

Birmingham, AL, USA

D. O. Bruff · D. P. Hardin

Nashville, TN, USA

J. S. Geronimo ( $\square)$

Atlanta, GA, USA

e-mail: geronimo@math.gatech.edu 